\title{
Building a Strategy Map for Khanh Hoa Aquatic Product Processing Enterprises
}

\author{
PHAN THI XUAN HUONG \\ Nha Trang University - huongptx@ntu.edu.vn \\ TRAN DINH KHOI NGUYEN \\ University of Da Nang - University of Economics - nguyen.tdk@due.edu.com
}

\begin{abstract}
ARTICLE INFO
ABSTRACT

Article history:

Building a strategy map helps an enterprise to clearly describe and

Received: interpret the content of the strategy, making a premise for selecting

Dec. 192013 key performance indicators (KPIs) and implementing the strategy based on new management models and modern strategic thinking in Received in revised form: accordance with the Balanced Scorecard approach. We proposed three groups of strategies and built three following strategy maps: (i)

Sep. 192014 strategy of developing high added-value products, (ii) strategy of ensuring the possibly lowest international outsourcing cost, and (iii) Accepted:

Jun. 28. 2015 strategy of target customer orientation. This paper is intended as a contribution to change the old strategic thinking of Khanh Hoa aquatic product processing enterprises and help them to navigate and Keywords: describe the strategy clearly and to develop sustainably in a globally competitive context.
\end{abstract}

Strategy map, aquatic

product processing,

Khanh Hoa, strategy description, balanced scorecard. 


\section{Problem statement}

Strategy oriented toward long-term competitive advantages is clearly performed when competitive factors exist. Previously, many aquatic product processing enterprises in Khanh Hoa was able to exist and develop without any business strategy by making the best use of market opportunities during early periods of economic reform, geographically convenient location, and abundant resources. In recent years these advantages have gradually disappeared, which requires processing enterprises to build up suitable strategies. At present, however, many seafood enterprises in Khanh Hoa have no much interest in planning and conducting such strategies. Most of them simply make annual plans for revenue, outputs, costs, and profits. Some have strategies, but these are examined only by firm owners without being put in black and white and disseminated among corporate departments and all employees.

It would be unsuitable and difficult to gain efficiency in the current competitive environment from the lack of business strategy and individually-determined strategies. Enterprises, therefore, should change their strategic thinking to adapt to the new environment. Their success depends on a collective rather than an individual. Thus, the application of a new management model and modern strategic thinking through Balanced Scorecard (BSC) is a new direction for enterprises.

BSC is a modern management tool for managing effectively and connecting work of each member with common strategy and objectives of the organization. The breakthrough of BSC tool is a change from a measurement system to a strategic communication tool via strategy map.

A strategy map is considered a tool to analyze strategies, a crucial component of BSC system, and an intuitive tool reflecting all core objectives that enterprises should achieve during their implementation of business strategies. In addition, it shows the causal relationships between core objectives. Building the strategy map is one of extremely important duties for organization's executive board to implement their strategies via BSC. Thus, the study has the following practical meanings: (i) to help enterprises carry out their strategies (from identifying objectives, action plans, and duties for the whole enterprise and each member, to measuring corporate performance); and (ii) to help increase competitive advantages and ensure a sustainable development for Khanh Hoa aquatic product processing industry. 


\section{Theoretical bases and methodology}

\subsection{Theoretical bases}

The strategy map, which did not exist in original version of the Balanced Scorecard, is added to the new one designed by Kaplan and Norton (2003). The Balanced Scorecard is a set of measures used for evaluating the corporate performance, including financial and non-financial measures on customer, internal business processes, learning and growth, thereby aligning the vision and strategy of the organization to specific goals through clear targets by setting performance measurement system (Kaplan \& Norton, 1992). Also according to Kaplan and Norton (2004), a strategy is not a single management procedure. The strategy map and balanced scorecard are steps of the reasonably continuous series, showing how strategic value and results are created. They affect the company or organization from a mission declared by senior executives to specific tasks carried out of every individual. The strategy map shows a connection between company's mission, vision, and core values and employees' objectives and action, thereby generating values for the company.

To make effective strategies, companies should initially describe and envisage their strategies because they cannot measure what they cannot describe. Once strategies cannot be measured, they cannot be managed. According to Niven (2002), the strategy map is used to describe strategies (Figure 1) and considered a strong communication tool helping related members to understand and implement strategies. Kaplan and Norton (2004) showed that building the strategy map is to create the causal relationship between objectives and factors affecting the company's final objective. Contents of building the strategy map include the following steps:

Step 1: Define general objectives for each strategy

Step 2: Set specific strategic objectives

Step 3: Build a causal relationship between objectives and draw the strategy map.

\subsection{Methodology}

This paper uses mainly a case study approach (Le \& Truong, 2012), analyzing context of eleven aquatic product processing enterprises to clarify and solve mentioned 


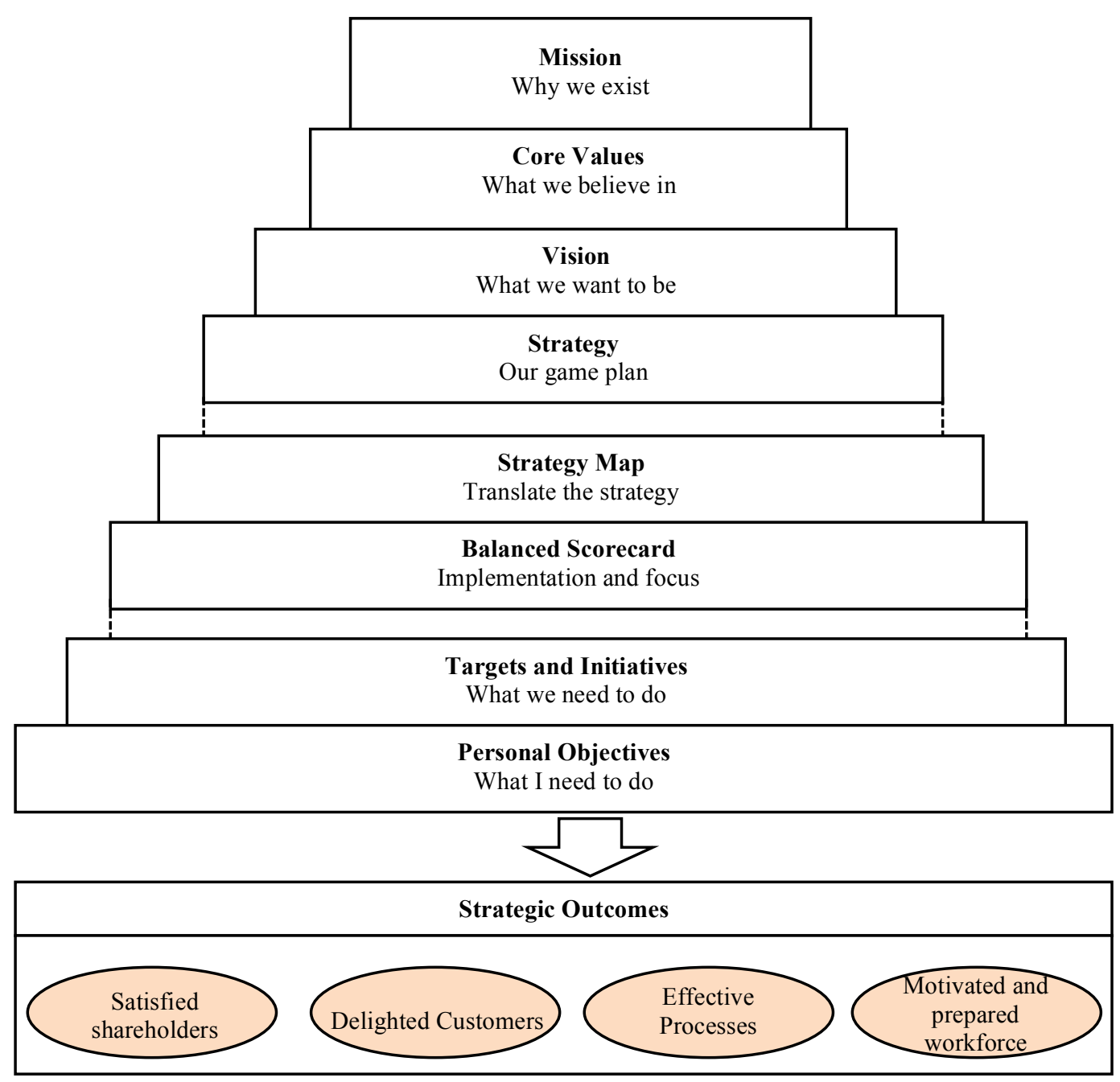

Figure 1. Strategy map in management series based on value and BSC approach Source: Kaplan \& Norton (2011, p. 56)

problem. A half of these core enterprises are recognized as prestige export companies by Ministry of Industry and Trade. They are leading exporters of aquatic products in Khanh Hoa. Their sizes, staple exports and export markets represent all common characteristics of seafood processing industry in Khanh Hoa.

In-depth interviews are conducted with 15 senior managers including directors, vice-directors, or sales managers of 11 selected companies in order to identify their 
strengths, weaknesses, opportunities and threats, products and market, all aspects of balanced scorecard, and especially sound out their strategies, visions and implementation of strategy. By communicating directly and using semi-structured interview method (qualitative research), in-depth interviews aim at exploring managers' views on aforementioned issues, thereby suggesting plans to build strategy map for Khanh Hoa aquatic product processing enterprises. In-depth interviews try to cross-check information from enterprises and supplement remarks on how Khanh Hoa aquatic product processing enterprises build and implement their strategies, which may clarify strategies of selected companies. This is a sustainable basis for identifying strategies they are pursuing and implementing.

In addition, the paper also uses a deductive approach based on statistical data from surveys of enterprises' performance through Likert questionnaires to identify enterprises' characteristics. Primary data are collected by sending 80 questionnaires to members of executive boards who really know enterprise's strategies inside out and play an important role in building it. There are 48 questionnaires sent back from 25 out of 30 aquatic products processing enterprises participating in the survey. These questionnaires are analyzed to obtain reliable information about 25 surveyed enterprises. If answers from members of the same company are in conflict with each other, respondents will be interviewed again to obtain final answers.

In an inductive approach, researchers examine grounded theory, use circumstances, observations, and interviews to collect data, analyze them, and build models (namely strategy maps for enterprises).

Moreover, statistical analysis and comparative methods are also employed to reach implications on research results, and survey data are processed by using logical processing method in connection with data processing software. 


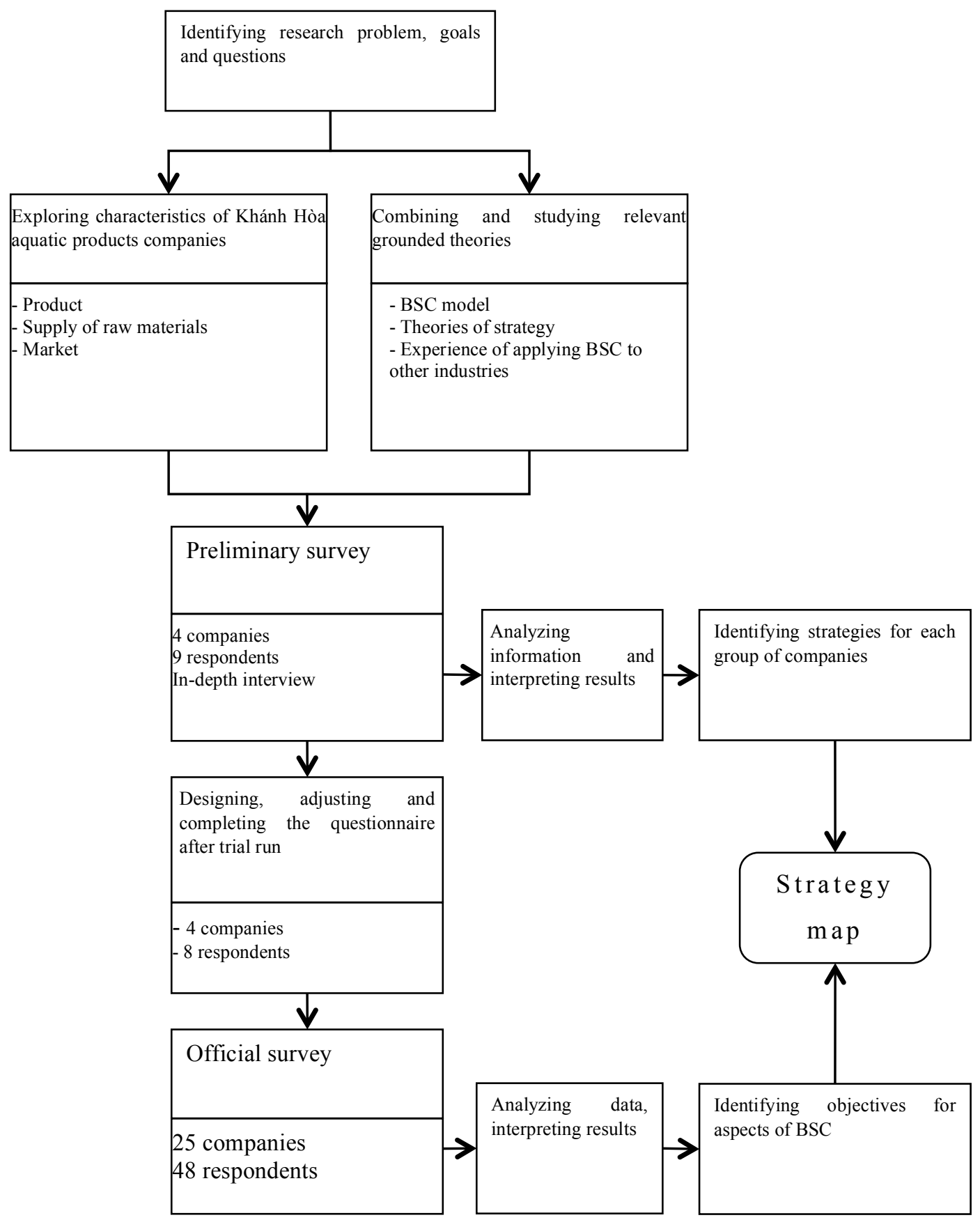

Figure 2. Research procedure 


\section{Discussion and recommendation}

\subsection{Results of survey of business and manufacturing strategy of Khanh Hoa aquatic} product processing enterprises

The authors interviewed senior executives of enterprises to gather facts about their business strategies. The survey results show that the corporate business strategies have the following features in common:

- All these executives think they had clear business strategies.

- Their strategies are mainly based on long experience in governance, great acumen in collecting and processing information, as well as subjective and personal judgments.

- These business strategies are not written down and disseminated among employees, even to members of executive board. Most employees only learn about the strategies through annual plans with specific objectives.

The survey results show that Khanh Hoa aquatic product processing enterprises, at present, are building their strategies based on experiences, which make it difficult to build the strategy map as well as apply BSC to these enterprises. Failure to disseminate business strategies among employees also limits their understanding and support, which prevents enterprises from generating a joint effort to achieve their objectives. Moreover, a strategy based on personal and sentimental judgments is not as persuasive as a factbased strategy. This problem can cause enterprises to make certain mistakes and fail to take opportunities timely and make use of enterprises' resources when forming and building the strategies.

To explain why they do not publicize their strategies, the senior managers say that revealing the strategies may provide company's rivals with some advantages. Moreover, disclosure of strategic stages allows rivals to know the enterprise better. That is the reason why employees only know short-term objectives instead of approaching the company long-term goals and direction.

\subsection{Strategy recommendation for Khanh Hoa aquatic product processing enterprises}

Through in-depth interviews with senior managers of 11 aquatic product processing enterprises in Khanh Hoa about building and implementation of business strategies, and Porter's concepts of three generic strategies (Porter, 1985), we suggest three following groups of strategies for aquatic product processing enterprises: 


\section{Table 1}

Results of survey of business missions, visions and strategies of Khanh Hoa aquatic product processing enterprises
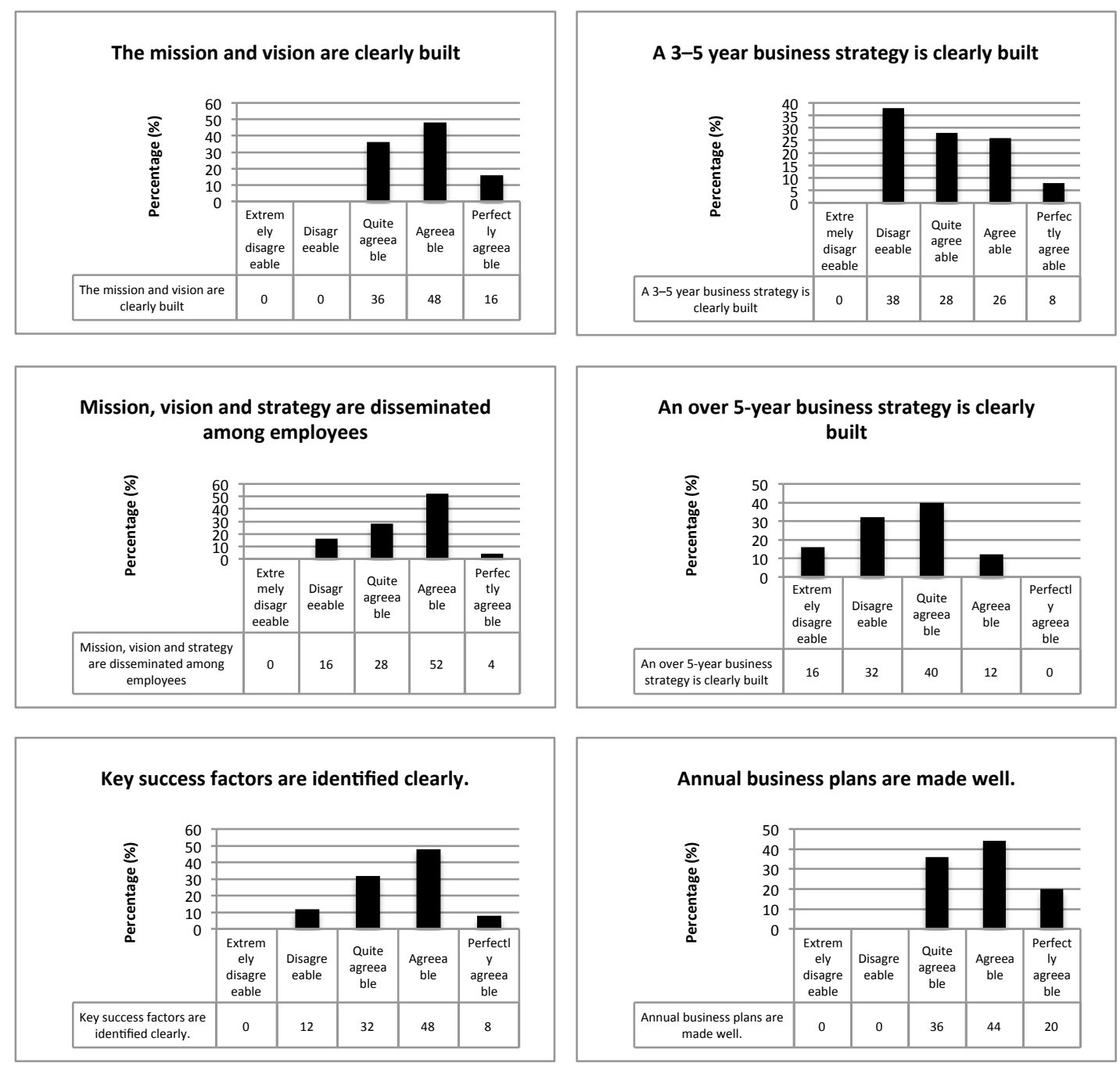

Source: Author's survey

3.2.1. Strategy to develop high added-value products

Cafico, F17, Thong Thuan, and Dai Thuan are enterprises that are suited to the strategy to develop high added-value products. 
This strategy is one of the ways to create differentiation that aims at making unique products in the industry and targeting relatively price-insensitive customers. This differentiation strategy requires that a company must have certain advantages such as a relatively large size in its industry or adequately well-known brand.

Making high added-value aquatic products can save $50 \%$ of materials, and increase their prices by $30-40 \%$ higher than raw products (Anh Tuan, 2011). Breaded shrimp, for example, includes main ingredient (shrimp, accounting for $50-60 \%$ of total materials), flour (accounting for some $50 \%$ of total materials) and other flavors and additives; therefore, with the same amount of shrimp, a company can produce a volume of products twice as much as frozen PD shrimp (peeled and deveined shrimp) and price can be $30-40 \%$ higher. This is also a major motivation for enterprises to choose to make high added-value products.

3.2.2. Strategy to offer the possibly lowest international outsourcing cost

This strategy is oriented toward lower production cost, emphasizing standardized products with unit cost suited to price-sensitive customers.

Enterprises that follow this strategy have cost advantage but face difficulties in accessing sources of raw materials and ensuring their market shares. Thus international outsourcing may be an optimal way to help enterprises reduce risks. When doing subcontract jobs, they can purchase materials as required by customers or produce goods of their own design and sell them to brokers or commercial companies. Selling goods to commercial companies may save enterprises from worrying about export procedures while using materials as required by customers helps them avoid the responsibility for microbiological problems with sources of raw materials.

Several companies adopting this strategy are Hai Vuong, Hai Long, Tin Thinh, and Thinh Hung.

3.2.3. Strategy to meet standards required by targeted customers

This is one of directions of target-centered strategy that aims at satisfying needs of small groups of customers.

This strategy is usually chosen by small-size companies that do not have many prominent advantages. It can be a suitable strategy for enterprises that tend to enter such less-demanding markets as Taiwan and China, or have no resources for finding footholds in markets requiring export code like EU countries, or want to satisfy orders 
for seafood of different types and sizes. This strategy is considered to be suitable for Khapesco, Binh Them, and LongShin.

\section{Building strategy maps}

Building strategy maps for aquatic product enterprises is to set the causal relationship between objectives and main duties and their influential factors, and additionally clarify impacts on the implementation of duties to achieve objectives as well as relationships between duties. Based on strategies of enterprises in each group, the paper identifies common characteristics of each group, thereby forming strategy maps based on their own features.

For three groups of strategies described in Subsection 3.2, the authors develop three respective strategy maps to describe strategy visually and disseminate it among executives and employees, helping them understand the strategies easily.

\subsection{Strategy maps for developing high added-value products}

This strategy map emphasizes objectives in the internal business processes to meet product quality standards (Figure 3). Important internal processes involve the following objectives:

Controlling input materials

Enterprises that are interested in high added-value products should consider materials quality as their first concern. Controlling well volume of input materials can help enterprises maintain the desirable capacity, avoid stagnation caused by shortage of raw materials, execute customers' orders timely and improve customer relationships. Additionally, good raw materials can reduce wastage, increase labor productivity (processing procedure occurs faster with good materials) and help to cut cost. Thus, the effective control of input materials produces a considerable impact on the implementation of competitive price in the customer perspective and supports the implementation of reasonable growth of profits in the financial perspective.

Managing well relationships with suppliers

Good supplier relationship management helps enterprises reduce risks when purchasing materials, maintain an opportunity to buy high-quality materials at reasonable prices, and produce good products at competitive prices. Therefore, enterprises can satisfy demands of customers, even the demanding ones, supporting the 
implementation of good customer relationship management and competitive prices in the customer perspective.

Developing domestic market network

Developing domestic market network for high added-value products through supermarkets and retail outlets can help enterprises take an advantage of domestic market in order to increase sales of high added-value products, contributing to an increase in sales of high added-value products and in profits in the financial perspective. Additionally, this can support the horizontal objective of increasing proportion of high added-value products.

Increasing proportion of high added-value products

This practice can help enterprises aim at high added-value products. This strategy also helps achieve an increase in sales of these products in the financial perspective.

Improving $R \& D$ activities

If enterprises want to make high added-value products, $R \& D$ activities play an important role in innovation in value chain of internal process. An enterprise should have a department specializing in seeking new type of product, making and adjusting designs to customer's demands to create a good public image and prestige to customers. This effort helps improve customer relationship management and increase export revenue of high added-value products in financial perspective.

Regarding learning \& growth, the objective of maintaining skilled, experienced labor force is a firm foundation to control input materials, manage supplier relationship and streamline production. 


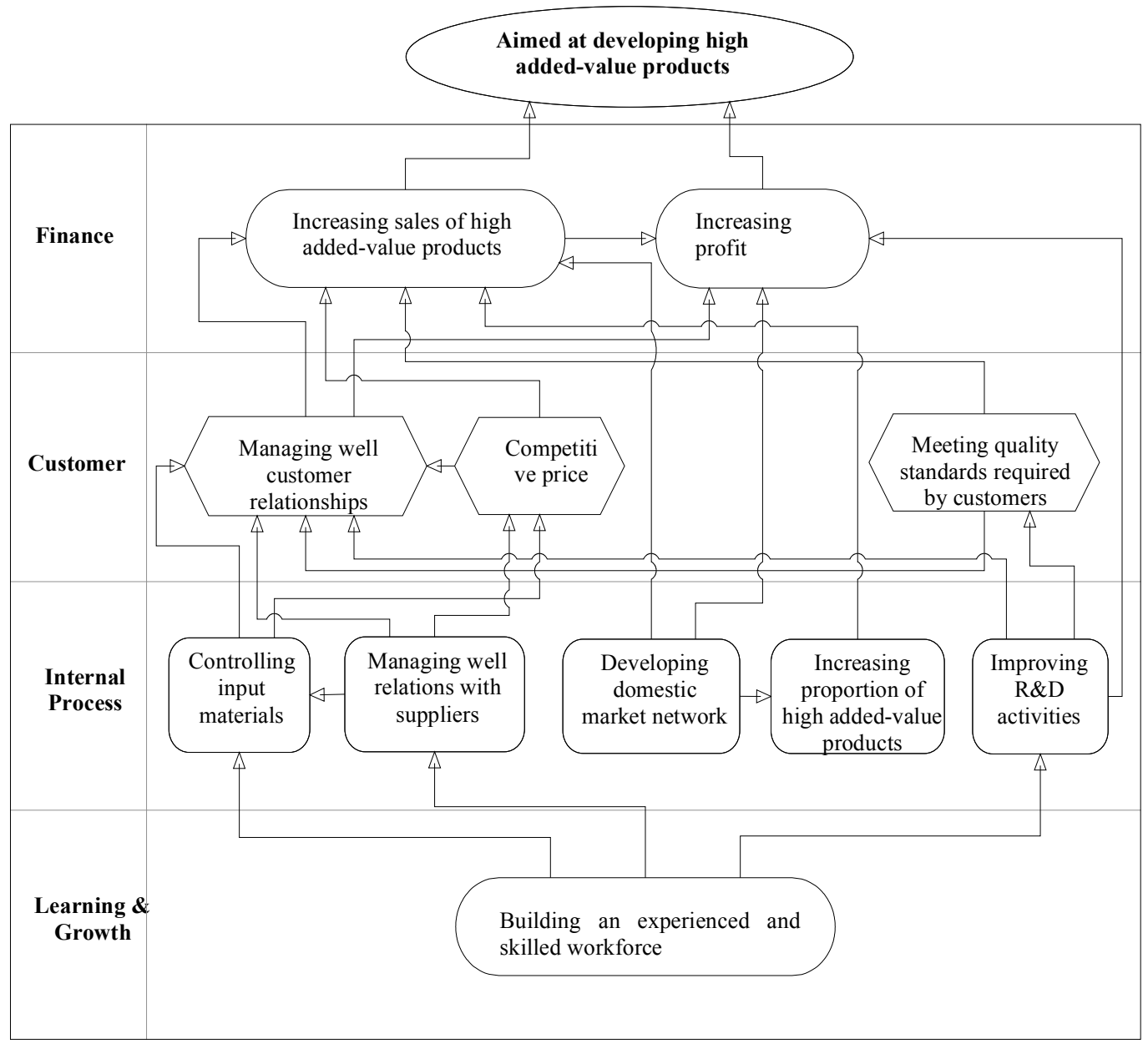

Figure 3. Strategy map for development of high added-value products

4.2. Strategy map for the enterprises that offer the possibly lowest international outsourcing cost

Lay-out of strategy map in Figure 4 shows aquatic product processing enterprises that want to be leaders in international cost of outsourcing tend to focus on the objective of cutting cost to obtain competitive outsourcing prices (Figure 4).

The crucial factor, customer, includes the following objectives:

Competitive cost of outsourcing 
Implementation of this objective may provide enterprises with a basis for leading the way in international outsourcing cost, and competitive cost of outsourcing supports the horizontal objectives of good customer relationship management and higher export revenue in financial perspective.

Good customer relationship management

This objective can help enterprises gather important information from customers, thereby creating customers' trust by satisfying their demands as much as possible. With this objective, therefore, in the financial perspective enterprises can achieve two objectives of increasing reasonably both export revenue and profits.

Product quality meeting customers' demands

Such demanding markets as the EU and US require a very high quality of aquatic products; hence, the standardization of quality management system is always considered customers' major concern. This objective supports good customer relationship management (customer perspective) and reasonable increase in export revenue (financial perspective).

Internal process involves the following important objectives:

Saving electricity expense

Electricity expense is a crucial factor in enterprises' total production cost. Thus, saving electricity expense may reduce production costs, thereby achieving competitive costs of outsourcing in the customer perspective.

Saving labor cost

Enterprises should pay much attention to improvement in the labor cost which is considered as a very important factor for enterprises to become leaders in international outsourcing costs. 


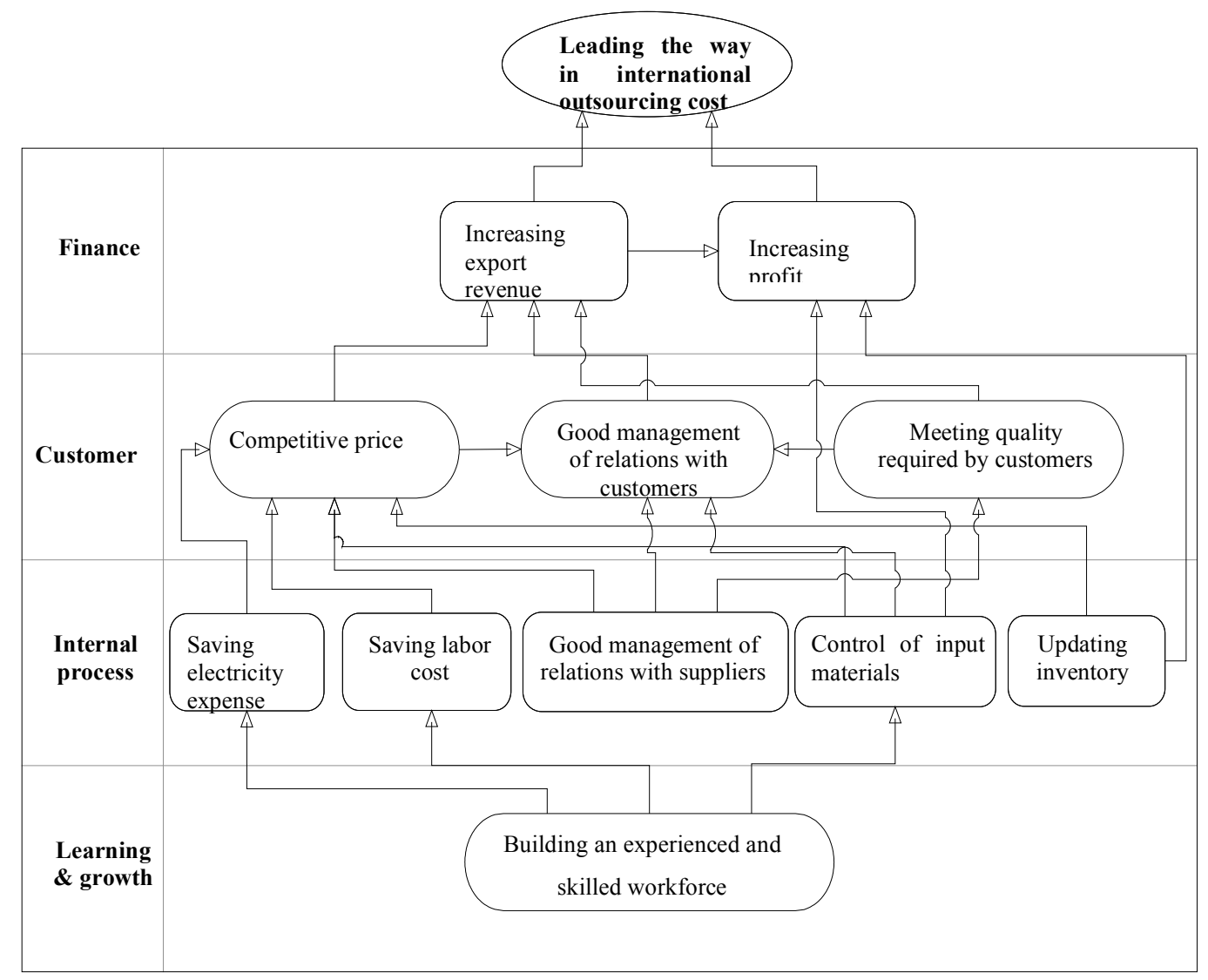

Figure 4. Strategy map for leaders in international cost of outsourcing

\subsection{Strategy map for enterprises oriented toward target customers}

Enterprises pursuing the strategy to meet standards required by target customers strive to satisfy specific demands of customers in types of product (Figure 5).

Customer perspective includes the following noticeable objectives:

Fulfilling orders for goods of different types and sizes

This objective needs to be emphasized so that customers can see enterprises' typical features. It makes it easier for enterprises to ensure a market niche by specializing themselves in fulfilling orders for goods of different types and sizes. Large enterprises do not want such orders while smaller ones cannot fulfill them. 
Achieving this goal will support the horizontal objectives of not only good customer relationship management but also a reasonable increase in export revenue in the financial perspective.

Meeting HACCP guide for aquaculture industry

The enterprises oriented toward standards required by targeted customers only concentrate on less-demanding markets because they do not yet have enough resources to consider investment in such markets asking export codes as the EU; therefore, they only need to meet HACCP guide for aquaculture industry. This objective, however, still impacts on customers' concern. Thus, achieving successfully the objective will support customer relationship management (in the customer perspective) and a reasonable rise in export revenue (in financial perspective).

Internal process includes the following main objectives:

Controlling the inventory after completion of contract

Inventory management can help enterprises control the volume of surplus after completion of contract and make plan to use it. This objective supports fulfillment of orders for goods of different types and sizes (customer perspective) and cuts in cost as a horizontal objective (financial perspective).

Updating the inventory

Updating the inventory can reduce any unnecessary cost of storage, making organizations handle inventory on their own initiative and keep it at suitable level. Thus, implementation of this objective may improve the horizontal objective of cutting costs and the one of fulfilling orders of various types and sizes in the customer perspective.

Cutting the costs

This objective emphasizes reduction in costs in all possible ways to achieve reasonable increases in revenue in the financial perspective. 


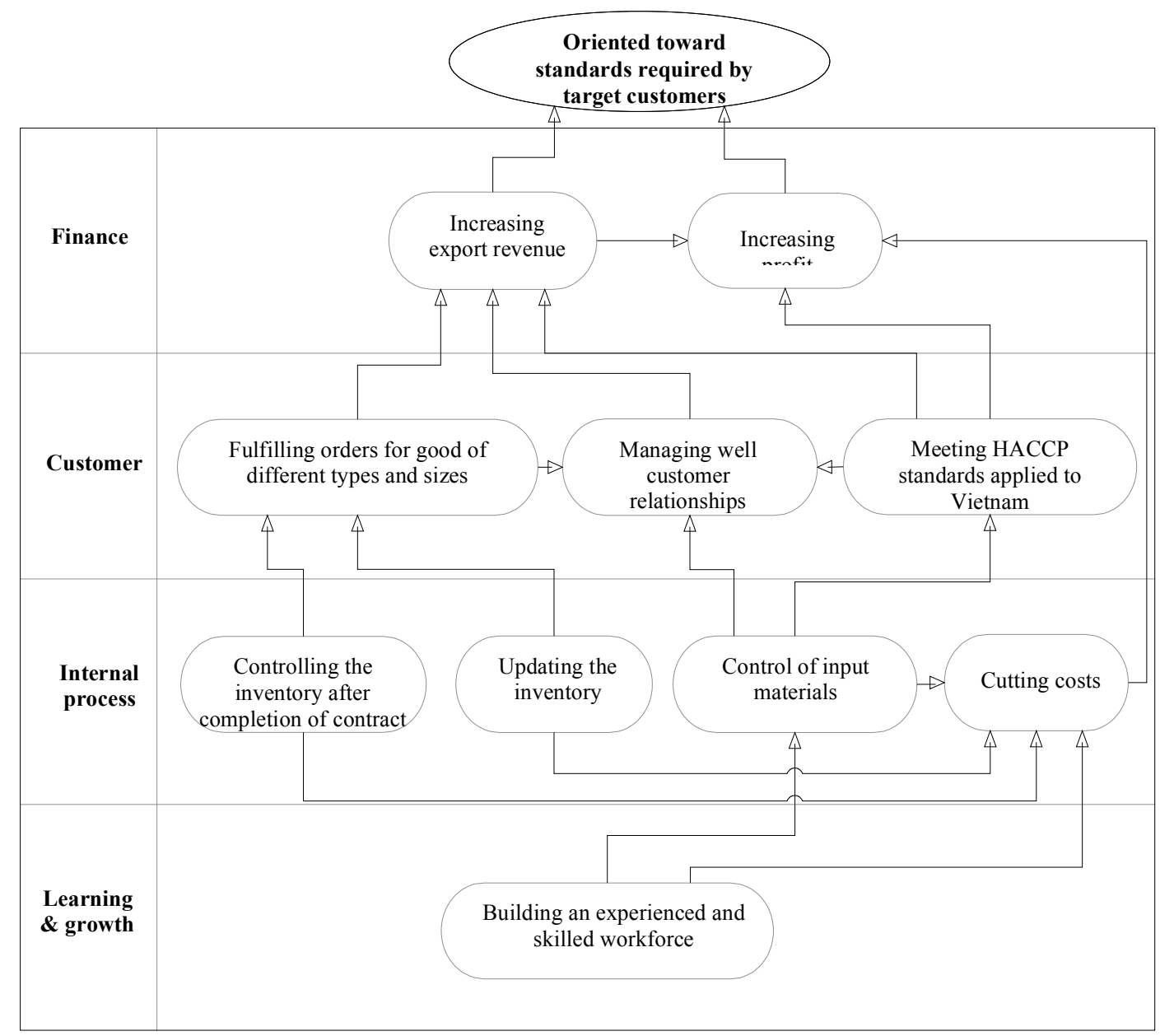

Figure 5. Strategy map for enterprises focusing on target customers

\section{Conclusion}

The study suggests three groups of strategies for Khanh Hoa aquatic product processing enterprises and builds three strategy maps: (i) Strategy to develop high added-value products; (ii) Strategy to lead the way in international cost of outsourcing; and (iii) Strategy to meet standards required by target customer. This is the crucial basis considered as a precondition for enterprises in Khanh Hoa to build Key Performance Indicators (KPI) and conduct strategies based on BSC. Strategy map is regarded as a core component of balanced scorecard used for describing strategies; 
generating values and help enterprises connect business performance, measures and KPI, thereby obtaining sustainable and stable development in a period of keen competition and economic fluctuations. To apply successfully BSC, aquatic product processing enterprises in Khanh Hoa need attend the following conditions:

- A new view on publication of strategies: Competitive rivals are not always able to imitate the strategies when they are publicized because successful implementation of the strategies depends more on various factors such as internal resources, characteristics, and strength of the enterprises than on executives' will. To survive competition, in addition, all enterprises want differentiation and try to achieve it. The practice of following trends or imitating others is no longer appropriate in the world of modern business. Publication of the strategies, hence, also encourages rivals to choose other strategies because they do not want duplication.

Moreover, a clear and scientific orientation can make the enterprises more professional in the eyes of customers and business partners as well. Additionally, dissemination of strategies among employees would show the trust enterprises put in employees, which helps generate a two-way collaboration, raises the employees' pride in the enterprise, and encourages them to do well their jobs. Perhaps, this practice is an increase in the intangible value to enterprises when they inform relevant parties of their policies.

- Process of measuring achievement of objectives in every stage should be established for the whole company and each department as well. Consequently, implementation of the strategy map of each group is possible.

- Innovations in information system for enterprises as a whole help them collect non-financial information in order to value results of the implementation of strategies based on targets in the strategy map. This is one of the key factors without it the strategy is only an impractical document. Implementation of enterprise resource planning (ERP) is the best way to apply BSC in a long term.

- Implementation of the strategy should be always conducted in every stage and regularly adjusted in the long term. Thus, it is necessary to organize step by step to match each stage of the strategy implementation.

- Communication of strategies to all departments as well as employees is considered as an indispensable factor, making all of them follow the enterprise's strategies. Additionally, reward system should connect with achievements estimated according to 
targets set by the strategy map. This is a way to improve potential competitiveness of every enterprise in the context of deep international integration

\section{References}

Anh, T. (2011). Export of seafood in 2011: Worries after achieving planned targets (in Vietnamese). Retrieved November 18, 2011 from http://www.baokhanhhoa.com.vn/kinhte/201112/xuat-khau-thuy-san-nam-2011-ve-dich-nhung-van-lo-2121152/

Kaplan, R. S., \& Norton, D. P. (1992). The balanced scorecard - Measures that drive performance. Harvard Business Review, 70(1), 71-79.

Kaplan, R. S., \& Norton, D. P. (2011). Strategy maps (in Vietnamese). HCMC, Vietnam: Tre Publisher.

Kaplan, R. S., \& Norton, D. P. (2004). Strategy maps: Converting intangible assets into tangible outcomes. Boston: Harvard Business School Press.

Le, V. H., \& Truong, T. T. A. (2012). Research methods in business (in Vietnamese). HCMC, Vietnam: Tai chinh Publisher.

Niven, P. R. (2002). Balanced scorecard step-by-step: Maximizing performance and maintaining results. New York: John Wiley \& Sons.

Porter, M. E. (1985). Competitive advantage. New York: Free Press. 